\title{
The Vulnerable Are Not (Necessarily) the Poor
}

\author{
Sanghamitra Bandyopadhyay \\ Queen Mary University of London, \\ and STICERD, London School of Economics
}

October 1, 2012 


\begin{abstract}
In this paper I examine the concept of "vulnerability" within the context of income mobility of the poor. While the concept of poverty is well developed, the concept of vulnerability is less established in the economic literature. I test for the dynamics of vulnerable households in the UK using Waves 1 - 12 of the British Household Panel Survey and find that, of three different types of risks for which I test, household-specific shocks and economy-wide aggregate shocks have the greatest impact on consumption, in comparison to shocks to the income stream. I find vulnerable households up to at least 10 percentile points above the poverty line. Savings and earnings from a second job are not significantly associated with smoothing consumption of all vulnerable households. The results strongly indicate that income transfers and benefits assist the vulnerable in smoothing consumption. Thus, traditional poverty alleviating policies are not likely to assist the vulnerable.
\end{abstract}

JEL codes: I3, I32, I38.

keywords : income variability, vulnerability, poverty, insurances.

Acknowledgement 1 I am grateful to Filippos Petroulakis and Alex Teytelboym for excellent research assistance. I thank Frank Cowell, Tim Smeeding, Albert Marcet, Peter Neary and Roberto Zelli for many useful suggestions. I have also benefitted from suggestions from seminar participants at Oxford University, London School of Economics, IAE Barcelona and at the Royal Economic Society, Econometric Society and IARIW conferences. All errors are mine. 


\section{Introduction}

In recent policy discussions, the importance of identifying the vulnerable has risen considerably. While newspapers and policy reports clearly distinguish between those who are "poor" and "vulnerable", these concepts are not fully separate in their treatment in the economic literature. For instance, in the aftermath of the summer 2011 riots in the United Kingdom, discussions in the mass media frequently focussed on the uncertainties of those who are poor and "near-poor", as well as which policy measures ought to be implemented to prevent the near-poor from succumbing to the effects of the current global economic crisis. ${ }^{1}$ Similar discussions of economic insecurity and unemployment have also occupied newspapers in the United States, much of the Euro-Zone, and even less affected emerging markets such as China, Singapore, India, Brazil and Argentina. The global economic crisis increased world unemployment from 178 million in 2007 to 206 million in 2012 (ILO (2012)), bringing economic insecurity to the forefront of policy discussions worldwide.

While a well defined poverty line exists by which researchers and policy makers alike can count the number of the poor ${ }^{2}$, there is no agreed definition on how to count the "vulnerable" or the "near-poor" in the economic literature. In this paper I will highlight who are the UK's "vulnerable" and distinguish them from the "poor" using the British Household Panel Survey. I use the British Household Panel Survey as it provides a continuous panel of households' consumption and income streams, alongside an array of household level characteristics and of their access to several credit and asset variables.

The idea of the vulnerable as being distinct from the poor is not new. That precariousness is welfare reducing, even if one is not currently poor, has occupied social and economic literature for decades, if not for over a century. Frederich Engels described Victorian England: "True, it is only individuals who starve, but what security has the working-man that it may not be his turn to-morrow? .... He knows that every breeze that blows, every whim of his employer, every bad turn of trade may hurl him back into the fierce whirlpool from which he has temporarily saved himself, and in which it is hard and often impossible to keep his head above water. He knows that, though he may have the means of living to-day, it is very uncertain whether he shall to-morrow."(Engels (1845),

\footnotetext{
${ }^{1}$ The investigation commissioned by the UK government to understand the causes of the riots in August 2011 was summarised in the report of the (Communities and Panel" 2012) Riots Communities and Victims Panel (2012), stating: "There are people 'bumping along the bottom', unable to change their lives".. "individuals were under considerable (economic) stress", and public action is required to help "500,000 forgotten families" in the UK. A key recommendation of the report was to make families more "economically resilient". Interviews with 270 rioters, undertaken by The Guardian newspaper and the London School of Economics, suggested income inequality, poverty, joblessness, economic insecurity and lack of hope for the future as some of the factors which fuelled the riots (Newsnight, BBC2, 2011)

${ }^{2}$ The discussion of a poverty index dates to the 1960s (see Sen (1976) for an account of the development of the poverty index) and continues to be fine-tuned using international PPP price index data as in Deaton (2010) and Chen and Ravallion (2010).
} 
page 26).

Over a century later, understanding vulnerability has occupied recent economic literature, (Townsend (1994), Cochrane (1991), Mace (1991), Amin et al. (2003), Dercon and Krishnan (2002), to name a few) whereby the vulnerable are identified by modelling the role of risks and uncertainty that impinge upon the household's consumption stream. In this paper I adopt an empirical definition of vulnerability: vulnerability is observed if an income shock or idiosyncratic shock translates into a shock to the consumption stream (as is also adopted in several of the aforementioned papers, described in Section 2). I identify the vulnerable in the UK with the British Household Panel Survey, using a panel regression approach, and with a particular interest in observing the effects of smoothing mechanisms, or "insurances" that may be at their disposal.

In particular, I use Feasible Generalised Least Squares to estimate significant vulnerability in the presence of smoothing mechanisms. These smoothing mechansisms are household characteristics (like household size, presence of an earning member in household), and access to savings and earnings from an extra job, amongst many others, and via having transfers and benefits captured in the following income concepts used: gross and net, monthly and annual. All three income concepts reveal different vulnerability dynamics, particularly close to the poverty line. I handle potential endogeneity in the model by extracting residuals from Mincer regressions (of income on years in education and age) to use as an instrument for income.

In order to identify the households that are vulnerable, I split the income distribution into several quantiles on the basis of several definitions, and identify location-specific vulnerability ${ }^{3}$. The significance of the smoothing mechanisms are observed to be different at different parts of the income distribution and over different time-horizons. These findings are new to the literature, where location-specific dynamics are not estimated in any of the earlier literature.

Where are the vulnerable? The location-specific dynamics reveal that they are not just below the poverty line (as one would expect), but also above the poverty line. Results in the paper show that there are vulnerable households up to at least 10 percentile points above the poverty line. Vulnerable households are also mobile: they move in and out of poverty. Also, idiosyncratic shocks appear to be equally evident in impacting upon consumption changes along with income shocks. All in all, the vulnerability dynamics revealed are not quite the same as one would obtain when performing similar analyses for a "determinants of poverty" study. This suggests that the policy package to be devised by the policy maker to assist the vulnerable is likely to be different than one for poverty

\footnotetext{
${ }^{3}$ In that respect, the work is close in spirit to that of income mobility (Shorrocks (1978), Jenkins (2011)). However, while the mobility literature focuses on the mechanisms that drives households both up and down along the income distribution, in this case I am more interested in those who are downwardly mobile. Another important point of departure from the mobility literature is that it rests on theories of risk and uncertainty.
} 
alleviation.

I build and contribute to the literature that already exists on identifying the vulnerable, where they identify risks which make households vulnerable. A large part of the extant work (particularly in the Development Economics literature) devotes itself to identifying the nature of the shocks which affect households' consumption stream and welfare, in particular with reference to Asia and Africa, using household level datasets (Amin et al. (2003), Dercon and Krishnan (2002) Maloney and Bosch (2004), Lokshin and Ravallion (2000)). The effect of income shocks on the consumption stream has already received substantial econometric treatment, particularly under a macro-econometric framework. These studies use inter-temporal choice models based on some variant of the permanent income hypothesis that investigates the presence, or absence, of consumption smoothing. Studies include those which measure the extent of consumption inequality (Blundell et al. (2008), Blundell and Preston (1998), Deaton and Paxson (1994)) as well as more direct tests of the presence of consumption smoothing in the face of income shocks (Japelli and Pistaferri (2006), Meghir and Pistaferri (2004)). These studies refine the econometric tools to track income shocks on consumption, but are not fashioned to identify the location of the vulnerable in an income distribution.

While the extant studies employ a large variety of empirical methods and risk modelling frameworks, there is no unified consensus on the identification of the vulnerable with the intent to provide policy prescriptions. I do not propose new empirical approaches but rather focus on identifying location-specific dynamics of the vulnerable and their responses to the smoothing mechanisms that are available to them. The three types of income concepts (i.e. monthly gross and net, and annual net) that are available in the BHPS have made it possible to identify the role of government welfare transfers and benefits that allow households to smooth consumption. These results have strong implications for policy. That the results reveal that savings and extra income from a second job have relatively little smoothing effect compared to that of the effect of transfers and benefits is significant for policy makers.

The paper is set out as follows. Section 2 sets up the empirical methodology for the identification of the vulnerable. Section 3 describes the data and the variables used for the analysis. Sections 4 and 5 present the results, Section 6 discusses the results and Section 7 concludes.

\section{Background: Who are the vulnerable?}

While there are several approaches to measuring vulnerability, how it is best measured and implemented is not fully agreed upon by researchers. There are several empirical approaches that have been undertaken to activate the idea of vulnerability. Much of its recent application, particularly in developing countries, stems from Townsend's (1994) 
framework. The paper addresses the efficacy of risk-sharing mechanisms in a full insurance framework. Townsend (1994) and several other empirical papers (Mace (1991), Cochrane (1991) were all based on a complete market structure as in the Arrow-Debreu model (1959, 64), much of which reject the complete market hypothesis. Mace (1991) studies inidividual consumption in the US and finds that growth and changes in the level of consumption is determined by the average consumption. Both Mace (1991) and Cochrane (1991) test for possible idiosyncratic, uninsured components that may impact upon levels or growth in consumption. In both cases, household incomes matter. Cochrane (1991) reveals that food consumption growth rates are lower for households that have experienced illness and job layoffs. In the developing country literature, Dercon and Krishnan (2002) also test the perfect risk-sharing model for Ethiopian households, and investigate public transfers via food-aid as risk-sharing arrangements. Here too the authors investigate idiosyncratic income shocks to test for testing risk-sharing where food aid to the village individuals functions as a "positive" income shock. They too find little evidence of perfect risk-sharing.

Ligon et. al. (2003) propose a different approach to measuring vulnerability which allows them to quantify the welfare loss associated with poverty as well as the loss associated with different sources of uncertainty, applied to Bulgarian panel data. Their measure can be decomposed into into distinct measures of poverty, aggregate risk, and idiosyncratic risk. With this approach they decompose the effects of each of these factors on levels of welfare - elimination of risks would only reduce welfare by $3 \%$, whereas elimination of poverty would improve welfare by $14 \%$. The effect observed via elimination of idiosyncratic shocks is insignificant compared to the size of the effect in reducing poverty and aggregate risk. Chaudhuri et al. 2002 and Pritchett et al (2001) use a measure of household vulnerability measured by the expected head count measure of poverty. Vulnerability as uninsured exposure to risk provides an alternative ex post assessment of welfare loss arising from the onset of an economic shock (Glewwe and Hall (1998), Maloney and Bosch (2004) and Lokshin and Ravallion (2000) all use this approach).

The approach used in this paper is in the spirit of macro models that incorporate the impact of risks on consumption (Cochrane (1991), Mace (1991) Meghir and Pistaferri (2004), Japelli and Pistaferri (2006), Blundell and Preston (1998)). The Townsend (1994) approach, which uses constant absolute risk aversion preferences, led to several developing country studies where the risks which mattered the most tend to be idiosyncratic in nature alongside the economy-wide shocks, such as inflation (Amin et al. 2003, Dercon and Krishnan 2002). Some of these studies have explicitly focused on the size of the effects of an income shock on the expected welfare of the household (Chaudhuri et al. 2002, Ligon and Schechter 2003). In short, in this study vulnerability is observed if a significant shock (an income shock, or idiosyncratic shock) is translated into a significant change in consumption. The empirical model estimated in this paper is therefore distinct 
from poverty-dynamics models that focus primarily on the mobility of the poor in terms of entry and exit rates, and on the identification of factors that trigger such transitions (Bane and Ellwood 1986, Jenkins 2000).

\subsection{The empirical strategy for measuring vulnerability.}

The empirical approach in this paper is to use a panel regression based on the approach used in Dercon and Krishnan (2002) and in spirit to that of Cochrane (1991) and Mace (1991) to identify the impact of risks and "insurances" that are available to households. I will identify the shocks which characterise income risks, by inclusion of a number of household characteristics and year-specific dummies which will capture idiosyncratic and economy-wide shocks. To identify location-specific dynamics of the vulnerable in the income distribution, not revealed in a cross-section regression towards the mean, I will break up the income distribution into a number of quantiles, on the basis of a number of definitions on the same lines as introduced in Bandyopadhyay and Cowell (2007). Focusing on quantile specific dynamics will reveal particularly vulnerable households near the poverty line. Finally, I will include a number of "smoothing mechanisms", which I loosely call "insurances", to observe their effects on the vulnerability dynamics. All the variables that are used in the analysis are discussed in the following data section.

\section{The British Household Panel Survey}

The BHPS extends for 18 waves and follows the same representative sample of individuals over a period of 18 years from 1991 to 2008. Each annual interview round is called a wave: in our study I use the first 12 waves of data, and each wave is principally householdbased, interviewing every adult member of sampled households. I work with 12 waves to maximise the complete availability of all the income (gross and net) and socio-economic variables that are used in the paper. Each wave consists of over 5,500 households and over 10,000 individuals drawn from 250 areas of Great Britain. The samples of 1,500 households in each of Scotland and Wales were added to the main sample in 1999, and in 2001 a sample of 2,000 households was added in Northern Ireland.

Our principal variables of interest are those of consumption, income, and household characteristics. The following variables are used for the empirical study.

The following variables have been used for the analysis:

- Expenditure on food, per week per household.

- Household income, per household

- Number of children in household. 
- Household size (i.e. number of individuals present in the household).

- Number of household members of employable age.

- Savings of household, monthly

- Earnings from a second job, monthly

- Tenured job, or not.

Expenditure on durables is only available for one wave, hence cannot be included in the analysis. The dataset has a complete panel with 1,510 individuals per wave.

Some of the variables have had to be constructed given the nature of the variables provided by the BHPS. Household consumption is only available for food consumption (with very sparse data on fuel consumption). Household expenditure per week per household is multiplied by 4 to obtain monthly food consumption, and divided by household size to obtain per capita estimates. Income variables are defined in three different ways, detailed in Bardasi and Jenkins (2004). There are three income definitions - monthly gross income, and two net income definitions - annual and weekly. Net annual income is provided over different time periods; for our study I have chosen income over the period 01.01.year to 31.12.year. Details of the derivation of net incomes in Bardasi and Jenkins (2004) is provided in the Appendix. The three different definitions of income give us different perspectives on the income smoothing process - while the monthly per capita income allows for all the time-specific shocks, the net current income takes into account the household weekly income net of the local taxes, while net annual income does the same over the period of 12 months (net of taxes and annual pension contributions) and allows for some income smoothing to have taken place. The relative importance of each time horizon will reveal itself with the estimations, discussed in the results later.

Table 2 presents the summary statistics for the variables I will be using for the estimation of vulnerability dynamics, estimated at 2000 prices. What is interesting to observe is that the dynamics of level values of consumption and income vary significantly from the inter-temporal changes of the same variable. The main aim of the empirical analysis will be to identify the associations of the changes in consumption in response to changes in income. The second half of the table presents the summary statistics of the truncated sample. The truncations are performed on the basis of outliers of the changes in household consumption - I truncate households for which changes in inter-temporal consumption exceed $+/-1$. It is clear from the right-hand side of the table that truncation does not remove the most extreme values of any variables other than dlxpmnpc, the variable used to condition the truncation. 


\begin{tabular}{lr}
\hline \hline \multicolumn{1}{c}{ variable name } & abbreviation \\
\hline real monthly expenditure, per capita & rxpmnpc \\
gross monthly income & y_gross \\
net monthly income & y_net \\
net annual income & y_net_ann \\
$\Delta$ ln y_gross & dlygross \\
$\Delta$ ln y_net & dlynet \\
$\Delta$ ln y_net_ann & dlynetann \\
household size & hhsize \\
number of children in household & nkids \\
number of earning members in household & nwage \\
savings per month & saved \\
earnings from second job & j2pay \\
whether job is tenured or not & tenured \\
dummy for wave n & dwaven \\
\hline
\end{tabular}

Table 1: Variables and abbreviations

\begin{tabular}{rcccccccc}
\hline \hline & \multicolumn{3}{c}{ FULL SAMPLE } & \multicolumn{5}{c}{ TRUNCATED SAMPLE } \\
variable & Mean & Std.Dev. & Min & Max & Mean & Std.Dev. & Min & Max \\
\hline realxpmnpc & 91.6 & 42.57 & 0 & 600 & 91.70 & 41.71 & 10.00 & 600.00 \\
y_gross & 601.19 & 438.92 & 0 & 21997.38 & 601.46 & 439.02 & 0 & 21997.38 \\
y_net & 675.35 & 757.29 & -50.42 & 22946.89 & 670.11 & 753.97 & -50.42 & 22946.89 \\
y_net_ann & 8834.83 & 9414.53 & 0 & 295634.3 & 8765.48 & 9376.60 & 0 & 295634.30 \\
dlygross & 0.05 & 0.38 & -6.81 & 4.27 & 0.05 & 0.38 & -6.81 & 4.27 \\
dlynet & 0.04 & 1.08 & -9.62 & 9.78 & 0.04 & 1.08 & -9.62 & 9.78 \\
dlynetann & 3.61 & 1.58 & -5.83 & 13.26 & 3.61 & 1.58 & -5.83 & 13.26 \\
hhsize & 2.60 & 1.43 & 1 & 10 & 2.62 & 1.43 & 1 & 10 \\
nkids & 0.74 & 1.10 & 0 & 6 & 0.75 & 1.10 & 0 & 6 \\
nwage & 1.09 & 1.15 & 0 & 6 & 1.09 & 1.15 & 0 & 6 \\
saved & 63.44 & 219.49 & 0 & 9999.0 & 63.60 & 220.03 & 0 & 9999.0 \\
j2pay & 19.04 & 157.50 & 0 & 9999.0 & 18.80 & 156.54 & 0 & 9999.0 \\
tenured & 0.69 & 0.46 & 0 & 1 & 0.69 & 0.46 & 0 & 1 \\
\hline
\end{tabular}

Table 2: Summary statistics 


\subsection{The cross-section unit of study}

The BHPS matches persons across waves and not households, thus presenting itself as a possible difficulty for using the data as a longitudinal panel. This however, is surmountable in that one can match households by the individual (i.e. personal) identity numbers. Again, tracking individuals as opposed to just households, is our preferred cross-section unit, as household compositions change over the waves (due to a household member leaving the household, or due to the interviewee not being available while survey was being undertaken). Our unit of consumption and income is that of the person, having taken into account household compositions. In tracking individual consumption and income I am also avoiding possible problems with economies of scale with large households. This however is dealt with when using equivalised quantities (results are available with author and not presented in paper for reasons of brevity).

\section{Vulnerability - initial glimpses}

Our first set of estimates involve estimating the following model:

$$
\Delta \ln c_{i t}=\nu \Delta \ln y_{i t}+\phi_{t} W_{t}+\varepsilon_{i t}
$$

where $c_{t}:=C_{t} / n$, denotes individual consumption (per-capita consumption of the household) in wave $t, y_{i t}$ is individual income (household income per capita) in wave $t$, and $W_{t}$ is a wave dummy, which equals one for observations at wave $t$, zero otherwise. $t$ varies from 1 to 12 , wave 1 corresponds to $t=1$, and wave 12 corresponds to $t=12$.

In addition to the wave dummies which capture year-specific aggregate shocks, I include household characteristics which may be significant determinants of household vulnerability dynamics. Variations in household size and composition may be seen as idiosyncratic shocks which have a direct impact upon the welfare of households. So I augment (1) as follows:

$$
\Delta \ln c_{i t}=\nu \Delta \ln y_{i t}+\phi_{t} W_{t}+\mathbf{X}_{i t} \gamma+\varepsilon_{i t}
$$

where $\mathbf{X}_{i t}$ is a vector of characteristics for individual $i$ in wave $t$. While this model tests for a particular specification of the utility function (namely, the CRRA specification), it empirically also lends itself better to the statistical problems which medium-to-long run time series data present. Differencing renders the variables as stationary, thus preventing any spurious co-trending from accounting for a positive and significant smoothing coefficient.

Finally to take into account the effects of possible insurances that may be at the behest of the households, I include a number of insurance variables. These are considered 
as variables that are likely to "condition" the relationship between $\Delta \ln c_{i t}$ and $\Delta \ln y_{i t}$.

$$
\Delta \ln c_{i t}=\nu \Delta \ln y_{i t}+\phi_{t} W_{t}+\mathbf{X}_{i t} \gamma+\mathbf{G}_{i t} \beta+\varepsilon_{i t}
$$

where $\mathbf{G}_{i t}$ is the vector of insurances for individual $i$ in wave $t$. These variables are savings, (lagged by one period, and by two periods to avoid effects of endogeneity), earnings from a second job, whether the household has access to credit, whether it already has a loan (indicative of its ability to have access to credit from banks), whether the individual has a mortgage, value of property owned, and whether the person owns credit cards.

I assume the error term to be uncorrelated with the RHS variables and to have zero mean. Let us also assume the following dynamic structure:

$$
\begin{aligned}
\operatorname{var}\left(\varepsilon_{i t}\right) & =\sigma_{i}^{2} \\
\operatorname{cov}\left(\varepsilon_{i t}, \varepsilon_{j t}\right) & =0 \\
\operatorname{cov}\left(\varepsilon_{i t}, \varepsilon_{i t^{\prime}}\right) & =0
\end{aligned}
$$

The error term can be expected to vary across individuals, because of heterogeneity in household size, consumption and income. The heteroscedasticity of the error term assumption is motivated by tests performed such as the White test (by regressing the square of the residuals on household characteristics and their squares and cross-products for each wave), where some heteroscedasticity is revealed. We estimate (3) taking into account the heteroscedastic nature of the error term using standard Feasible Generalised Least Squares (FGLS). $\sigma_{i}^{2}$ in equation 4 is given as:

$$
\sigma_{i}^{2}=\exp \left(\sum_{j} \beta_{j} z_{i j}\right)
$$

where the $z_{i j}$ are observables such as household size, number of children.

Several diagnostic tests performed on the residuals using standard panel data methods (i.e. allowing for a homoscedastic error term) do not suggest a strong presence of heteroscedasticity; nevertheless I use FGLS methods for estimation along with standard panel regression methods. Taking inter-temporal differences (i.e. of the regressand and principal regressor, $\Delta c_{i t}$ and $\Delta y_{i t}$ ) eliminates a source of correlation across time periods and there is little evidence of correlation of the differences across time periods. ${ }^{4}$ The GLS method used takes into account any residual correlation across panels that may still remain after the first-differencing. Equation (3) is estimated both under FGLS and the standard panel regression techniques.

\footnotetext{
${ }^{4}$ The correlation coefficients between $\Delta c_{i t}$ and $\Delta c_{i t-1}$, and $\Delta y_{i t}$ and $\Delta y_{i t-1}$ are not significant anywhere nor do I obtain a consistently significant Dickey-Fuller statistic.
} 
I have run the above models using both FGLS, and standard fixed and random effects panel regressions with all these insurance variables. Barring savings and earnings from second job, none of the other insurance variables are significant in the estimated models. I therefore only present results from the regressions including these two insurance variables.

\subsection{Insurance variables and endogeneity.}

To observe the effect of the insurances that are available to households, I may encounter some endogeneity due to the close relationship between age, education, income and saving. Including these variables separately as explanatory variables in equation 3 increases the possibility of further endogeneity due to the strong correlations between these variables. I first, therefore, take into account the effects of age and education on the levels (and variation) of income. For this, I will model what are known commonly in the literature as Mincer regressions ${ }^{5}$, and extract the effect of age and education on income, and use the residuals from these regressions as an instrument for income.

This method has two benefits. One, is to be able to extract the effects of age and education on income and use that component of income that is free from the effects of age and education. Second, on further including the insurance variables, such as savings, or access to credit, a further source of endogeneity is also dealt with here.

I run the following Mincer regression model to account for the variation in income that is governed by factors other than age and education:

$$
\ln y_{i t}=\alpha_{1}+\alpha_{2} a_{g e} e_{i t}+\alpha_{3} a g e_{i t}^{2}+\alpha_{3} a_{g e} e_{i t} * \text { school }_{i t}+\alpha_{4} \text { school }_{i t}+e_{i t}
$$

where, I estimate school as

$$
\operatorname{school}_{i t}=3 * \text { highest qualification } \text { achieved }_{i t}+5
$$

where "highest qualification achieved" is a scaling I propose based on the following:

- 5: Higher degree

- 4: Degree

- 3: A level/HND, HNC

- 2: CSE/O level

- 1: No academic qualifications.

\footnotetext{
${ }^{5}$ I thank Frank Cowell for this suggestion.
} 
$y_{i t}$ is income (monthly gross, monthly net and net annual) for individual $i$ in wave $t$, $e_{i t}$ is assumed to be an error term normally distributed, $N\left(0, \sigma_{e}^{2}\right)$.I now instrument income with the residuals from the regression 6 for the estimation of equation 3. Residuals are extracted for all three income types. To avoid similar issues of endogeneity, I lag the variables savings ${ }^{6}$. Earnings from second job is documented in the BHPS questionnaire as earnings in the week prior to the current week, therefore not requiring any further lagging. I observe that of all the "insurances" that have been included as regressors, only lagged savings is robustly associated with changes in consumption. To account for the length of the memory of income, I have also run a few specifications to observe the effect of lagged income differences, for which I have obtained the same dynamics as that of contemporaneous income first differences ${ }^{7}$. For each of the models that I have estimated, the Durbin-Wu-Hausman statistic does not suggest in any of the models that the use of standard panel methods would have been inconsistent (the F statistic is not significant in any of the models estimated). Likewise the Anderson LM test and Sargan tests for overidentification also do not result in a significant test statistic to suggest over-identification in any of the models estimated.

In the following section I will focus on the vulnerability dynamics specific to the location of households in the income distribution in light of these insurance variables.

\section{Locating the vulnerable in the income distribution}

I am particularly interested in the location of the vulnerable in the income distribution. This is important as not all cases where an individual's or household's current consumption is responsive to current income should be characterised as vulnerability. Richer agents respond to surprise positive income shocks by boosting their consumption, this is not to be characterised as "vulnerability". Likewise, the poor already under the poverty line are also not "vulnerable" in the sense we wish to define here, even though one may obtain a strong association between volatile incomes and volatile consumption for these households/quantiles. In other words, one can be both poor and "vulnerable" by the empirical definition set out earlier, but we are more interested in those who are not in poverty now but likely to slip into it.

To identify the dynamics in the neighbourhood of the poverty line and to compare dynamics in specific parts of the distribution I adopt the following procedure ${ }^{8}$. Specify a

\footnotetext{
${ }^{6}$ I was also motivated to use lagged values because of obtaining insignificant results with the current time period's savings as a regressor. It is clearly intuitive that last period's savings are more influential in deciding current period's expenditures.

${ }^{7}$ Results are obtainable from author on request and are not included here for reasons of brevity.

${ }^{8}$ This method is also used in Bandyopadhyay and Cowell (2007)
} 
set of intervals:

$$
I_{j}:=\left[q_{j}, q_{j+1}\right)
$$

where $0 \leq q_{j}<q_{j+1}<1$ and let them define a set of location-specific subsamples on which to estimate the model (3) using one of two methods. First, consider the households' starting positions in the income distribution according to whether they fall into interval $I_{j}$ by rank in the initial wave, Second, identify households that at some point in time have contact with $I_{j}$. Tables 3 to 5 presents results of the first method for fixed quantile groups throughout the income distribution; Table 6 and 7 compares the results for each of the two methods to examine the performance of the vulnerability model in the neighbourhood of the poverty line where the neighbourhood intervals $I_{j}$ are determined relative to the poverty line.

I first observe the distribution specific dynamics by observing the vulnerability dynamics at different parts of the income distribution. For this, I take the following fixed quantile groups as key "starter intervals": 20-40\%, 40-50\%, 50-60\%, 60-70\% and 70-80\% where, for example the $20-40 \%$ group includes all households who start at or above the 20th centile, but below the 40th centile. Tables 3 to 5 present results across the different quantile groups using the FGLS specification using three different income definitions: gross monthly, net monthly and net annual income. Two important observations are clear: first, that the vulnerability dynamics are clearly quantile-specific. The vulnerability dynamics differ across the income distribution. Second, the vulnerability dynamics are also sensitive to the definition of income. While there is some significant vulnerability for the gross income definitions for a number of quantiles (namely 50-60th and 60-70th), these are not so apparent in the net income definitions. For the net monthly income model, I obtain significant vulnerability for the 20-40th and 60-70th percentile, while for net annual, only for the 60-70th percentile.

In short, that the net income definitions yield little significant vulnerability are suggestive that net incomes (which are incomes net of the transfers and benefits for this sample) are successful in smoothing consumption. This highlights the importance of benefits and transfers for the vulnerable. We will return to the crucial policy implications of this finding later on.

Of the two insurance variables, I do not observe a great deal of significant association of these with changes in consumption. Lagged savings is not significant for any income definition. Earnings from a second job is significant for some of the specifications for all the monthly gross and net income types for the top three quantiles, but with a very small co-efficient. Of the household characteristics, I observe neither of the number of children and number of wage employable members in the family to be significantly associated with changes in consumption.

To summarise, significant vulnerability is particularly specific to the location in the 


\begin{tabular}{rrrrrrr}
\hline \hline$I_{j}:$ & $\mathbf{2 0 - 4 0 \%}$ & $\mathbf{4 0 - 5 0 \%}$ & $\mathbf{5 0 - 6 0 \%}$ & $\mathbf{6 0 - 7 0 \%}$ & $\mathbf{7 0 - 8 0 \%}$ & $\mathbf{8 0 - 1 0 0 \%}$ \\
\hline drygross & 0.015 & 0.001 & $0.057^{\dagger}$ & $0.057^{\dagger}$ & -0.002 & -0.002 \\
dwave2 & $0.075^{*}$ & $0.134^{*}$ & $0.088^{\dagger}$ & $0.097^{*}$ & $0.099^{*}$ & $0.099^{*}$ \\
dwave3 & 0.043 & 0.002 & 0.013 & $0.069^{\dagger}$ & $0.052^{\dagger}$ & $0.052^{\dagger}$ \\
dwave4 & $0.049^{\ddagger}$ & 0.010 & 0.048 & $0.060^{\ddagger}$ & 0.024 & 0.024 \\
dwave5 & 0.045 & 0.016 & 0.024 & 0.041 & 0.010 & 0.010 \\
dwave6 & $0.056^{\dagger}$ & 0.021 & -0.010 & 0.044 & $0.042^{\ddagger}$ & $0.042^{\ddagger}$ \\
dwave7 & 0.000 & $0.075^{\dagger}$ & $0.083^{\dagger}$ & $0.070^{\dagger}$ & 0.024 & 0.024 \\
dwave8 & $0.065^{\dagger}$ & 0.052 & $0.122^{*}$ & $0.10^{*}$ & $0.093^{*}$ & $0.093^{*}$ \\
dwave9 & 0.009 & -0.005 & -0.044 & 0.045 & -0.002 & -0.002 \\
dwave10 & 0.033 & 0.029 & 0.039 & 0.023 & -0.023 & -0.023 \\
dwave11 & $0.067^{\dagger}$ & 0.007 & 0.010 & 0.046 & $0.056^{\dagger}$ & $0.056^{\dagger}$ \\
nkids & 0.006 & 0.005 & 0.001 & 0.002 & 0.003 & 0.003 \\
nwage & -0.002 & -0.003 & 0.001 & -0.003 & -0.006 & -0.006 \\
tenured & -0.011 & 0.002 & 0.011 & 0.008 & -0.012 & -0.012 \\
lagsaved & 0.000 & 0.000 & 0.000 & 0.000 & 0.000 & 0.000 \\
lagj2pay & 0.000 & 0.000 & 0.000 & $0.000^{*}$ & $0.000^{\ddagger}$ & $0.000^{\ddagger}$ \\
cons & 0.003 & 0.014 & 0.000 & -0.015 & 0.026 & 0.026 \\
\hline Sargan & 0.000 & 0.000 & 0.000 & 0.000 & 0.000 & 0.000 \\
Anderson LM p-value & 0.000 & 0.000 & 0.000 & 0.000 & 0.000 \\
Durbin-Wu-Hausman & 0.871 & 0.783 & 0.634 & 0.657 & 0.711 & 0.976 \\
\hline Notes & $*:$ & Significant at the $1 \%$ level & & & \\
& $\dagger:$ & Significant at the $5 \%$ level & & & \\
& $\neq:$ & Significant at the $10 \%$ level & & & \\
\hline
\end{tabular}

Table 3: Vulnerability dynamics, selected quantiles for monthly gross per capita income

income distribution, and is also sensitive to the income definition.

It is also important to observe the temporal nature of vulnerability. For both monthly (gross and net) income definitions, I observe some significant vulnerability. However, for net annual income, I do not observe any significant vulnerability for any of the quantiles. This suggests that vulnerability is likely a short-term phenomenon. ${ }^{9}$

Location in the income distribution determined in a static manner, as above, has highlighted only some instances of vulnerability. The task therefore now is to implement a dynamic definition of location in the income distribution, pursued in the following section.

\footnotetext{
${ }^{9}$ The temporal nature of vulnreability has been further explored by splitting income into its transitory and permanent components. When the above models are estimated with the transitory component of the income, the vulnerability dynamics are again clearly exhibited. This again suggests that vulnerability is likely a short-term phenomenon. These results are not presented in this version of the paper, they were presented in a previous version of the paper, and are available from the author on request.
} 


\begin{tabular}{rrrrrrr}
\hline \hline$I_{j}:$ & $\mathbf{2 0 - 4 0 \%}$ & $\mathbf{4 0 - 5 0 \%}$ & $\mathbf{5 0 - 6 0 \%}$ & $\mathbf{6 0 - 7 0 \%}$ & $\mathbf{7 0 - 8 0 \%}$ & $\mathbf{8 0 - 1 0 0 \%}$ \\
\hline drynet & $0.014^{*}$ & 0.003 & 0.007 & $0.024^{\ddagger}$ & -0.006 & 0.005 \\
dwave2 & $0.082^{*}$ & $0.091^{\dagger}$ & $0.103^{*}$ & 0.092 & $0.098^{\dagger}$ & $0.102^{*}$ \\
dwave3 & $0.067^{\dagger}$ & 0.048 & $0.064^{*}$ & $0.068^{\ddagger}$ & $0.071^{*}$ & 0.035 \\
dwave4 & -0.013 & 0.054 & $0.060^{*}$ & 0.062 & $0.068^{*}$ & 0.023 \\
dwave5 & $0.049^{*}$ & 0.047 & $0.059^{*}$ & 0.064 & $0.082^{\dagger}$ & 0.015 \\
dwave6 & 0.032 & 0.045 & 0.049 & 0.049 & 0.050 & 0.010 \\
dwave7 & 0.021 & 0.039 & 0.052 & 0.051 & 0.051 & 0.054 \\
dwave8 & $0.066^{\dagger}$ & $0.080^{\dagger}$ & $0.101^{*}$ & $0.113^{*}$ & $0.129^{*}$ & $0.130^{*}$ \\
dwave9 & 0.032 & 0.030 & 0.029 & 0.016 & -0.021 & $-0.055^{*}$ \\
dwave10 & -0.011 & 0.039 & 0.046 & 0.056 & 0.063 & 0.016 \\
dwave11 & 0.036 & 0.023 & 0.050 & 0.042 & 0.061 & 0.042 \\
nkids & 0.000 & 0.003 & -0.002 & 0.001 & 0.001 & -0.002 \\
nwage & -0.006 & -0.004 & 0.003 & 0.001 & 0.003 & -0.006 \\
tenured & 0.005 & -0.009 & -0.009 & -0.001 & -0.001 & 0.008 \\
lagsaved & 0.000 & 0.000 & 0.000 & 0.000 & 0.000 & 0.000 \\
lagj2pay & 0.000 & $0.000^{\dagger}$ & 0.000 & $0.000^{\ddagger}$ & $0.000^{\ddagger}$ & $0.000^{\ddagger}$ \\
cons & 0.018 & 0.018 & -0.007 & -0.006 & -0.018 & 0.002 \\
\hline Sargan & 0.000 & 0.000 & 0.000 & 0.000 & 0.000 & 0.000 \\
Anderson LM & 0.000 & 0.000 & 0.000 & 0.000 & 0.000 & 0.000 \\
Durbin-Wu-Hausman & 0.715 & 0.673 & 0.563 & 0.675 & 0.671 & 0.982 \\
\hline Notes & $*:$ & Significant at the $1 \%$ level & & & \\
& $\dagger:$ & Significant at the $5 \%$ level & & & \\
& $\ddagger$ Significant at the $10 \%$ level & & & \\
\hline \hline
\end{tabular}

Table 4: Vulnerability dynamics, selected quantiles for monthly net per capita income 


\begin{tabular}{rcccccc}
\hline \hline$I_{j}:$ & $\mathbf{2 0 - 4 0 \%}$ & $\mathbf{4 0 - 5 0 \%}$ & $\mathbf{5 0 - 6 0 \%}$ & $\mathbf{6 0 - 7 0 \%}$ & $\mathbf{7 0 - 8 0 \%}$ & $\mathbf{8 0 - 1 0 0 \%}$ \\
\hline drynetann & 0.003 & 0.002 & -0.008 & $-0.012^{\ddagger}$ & -0.001 & 0.001 \\
dwave2 & $0.093^{*}$ & $0.104^{*}$ & $0.097^{\dagger}$ & $0.082^{\dagger}$ & $0.106^{*}$ & $0.107^{*}$ \\
dwave3 & $0.045^{*}$ & 0.004 & 0.051 & $0.073^{\dagger}$ & $0.079^{\dagger}$ & $0.055^{*}$ \\
dwave4 & $0.032^{\dagger}$ & 0.038 & 0.042 & 0.013 & $0.072^{\ddagger}$ & 0.033 \\
dwave5 & $0.043^{*}$ & 0.033 & 0.030 & $0.059^{\ddagger}$ & $0.065^{\ddagger}$ & 0.024 \\
dwave6 & $0.030^{\dagger}$ & 0.023 & $0.079^{\dagger}$ & 0.022 & $0.065^{\ddagger}$ & 0.019 \\
dwave7 & $0.035^{*}$ & 0.009 & 0.010 & 0.031 & $0.065^{\ddagger}$ & $0.067^{\dagger}$ \\
dwave8 & $0.088^{*}$ & $0.066^{\dagger}$ & 0.062 & $0.104^{*}$ & $0.126^{*}$ & $0.110^{*}$ \\
dwave9 & 0.009 & -0.003 & 0.045 & 0.031 & 0.045 & -0.042 \\
dwave10 & 0.015 & $0.045^{\ddagger}$ & 0.007 & 0.008 & 0.024 & 0.022 \\
dwave11 & $0.039^{*}$ & 0.010 & 0.051 & 0.030 & $0.068^{\ddagger}$ & 0.042 \\
nkids & 0.002 & -0.001 & 0.006 & 0.000 & 0.009 & -0.008 \\
nwage & -0.003 & -0.004 & $-0.013^{\ddagger}$ & -0.001 & -0.002 & -0.001 \\
tenured & -0.001 & 0.004 & 0.007 & 0.009 & 0.000 & -0.008 \\
lagsaved & 0.000 & 0.000 & 0.000 & 0.000 & 0.000 & 0.000 \\
lagj2pay & 0.000 & 0.000 & 0.000 & 0.000 & 0.000 & 0.000 \\
cons & 0.009 & 0.022 & 0.006 & -0.007 & -0.029 & 0.008 \\
\hline Sargan & 0.000 & 0.000 & 0.000 & 0.000 & 0.000 & 0.000 \\
Anderson LM p-value & 0.000 & 0.000 & 0.000 & 0.000 & 0.000 & 0.000 \\
Durbin-Wu-Hausman & 0.654 & 0.327 & 0.276 & 0.164 & 0.659 & 0.793 \\
\hline Notes & $*:$ & Significant at the $1 \%$ level & & & \\
& $\dagger:$ Significant at the $5 \%$ level & & & \\
& $\ddagger$ Significant at the $10 \%$ level & & & \\
\hline
\end{tabular}

Table 5: Vulnerability dynamics, selected quantiles for annual net per capita income 


\subsection{Dynamics around the poverty line}

I now focus on the vulnerability dynamics in the immediate neighbourhood of the poverty line. To identify these dynamics I need to define 1) a poverty line, 2) what defines proximity to the poverty line and 3) a criterion on the basis of which I define whether the household is "close" to the poverty line. ${ }^{10}$ I treat each in turn.

- Poverty line: The poverty line is defined to be at $60 \%$ of the median income. This is the standard approach adopted with reference to the UK.

- The poverty zone: I define a poverty zone, an interval $I^{*}$ defined relative to the poverty line. Let the proportion of households with incomes below $60 \%$ of the median be $q^{*}$. Since any particular specification of the poverty zone would be an arbirtrary choice, I take two separate $20 \%$ neighbourhoods of this value,

$$
I_{\mathrm{sym}}^{*}=\left[q^{*}-0.1, q^{*}+0.1\right)
$$

and

$$
I_{\text {asym }}^{*}=\left[q^{*}-0.15, q^{*}+0.05\right) .
$$

- Being at the threshold: For each version of the poverty zone $I^{*}$ I estimate the model for both "starts in poverty zone" case (sipz), where the household was in $I^{*}$ at the beginning of the panel, and for "ever in poverty zone" (eipz) case, where the household is in $I^{*}$ for at least one year covered by the panel. The eipz case is clearly one where there will be a much larger number of households.

I estimate our vulnerability model for each of the two interpretations of the poverty zone (sipz and eipz cases) using all three income definitions, and using the two interpretations of each poverty zone (symmetric and asymmetric poverty zones, $I_{\mathrm{sym}}^{*}$ and $I_{\text {asym }}^{*}$ ). In Table 6 I present the results of the sipz sub-sample. Significant vulnerability is now evident, particularly for symmetric subsamples around the poverty line. Here I obtain significant vulnerability for all three income definitions. Of the insurance variables, lagged savings is strongly significant for the net annual income definition. This result also holds for the eipz sample. This may be interpreted as savings having assisted as an insurance over the longer term, as opposed to the short-to-medium term. In Table 7, I observe the vulnerability dynamics of the eipz sample. Here there is significant vulnerability for only the gross income variable. The number of children and number of wage employable members in household are not significant again, though one of the the insurance variables, tenured, is significant for only one of the specifications estimated. For both sipz

\footnotetext{
${ }^{10}$ This approach is also undertaken in Bandyopadhyay and Cowell (2007).
} 


\begin{tabular}{|c|c|c|c|c|c|c|}
\hline & \multicolumn{2}{|c|}{ y_gross } & \multicolumn{2}{|c|}{ y_net } & \multicolumn{2}{|c|}{ y_net_ann } \\
\hline & Sym & Asym & Sym & Asym & Sym & Asym \\
\hline drincome & $0.041^{*}$ & $0.050^{*}$ & $-0.004^{*}$ & $-0.004^{\ddagger}$ & $0.010^{\ddagger}$ & 0.004 \\
\hline dwave2 & 0.013 & 0.041 & 0.027 & 0.048 & 0.033 & $0.054^{\ddagger}$ \\
\hline dwave3 & 0.032 & 0.039 & 0.039 & 0.047 & 0.043 & 0.050 \\
\hline dwave4 & 0.004 & -0.018 & 0.011 & -0.009 & 0.018 & -0.005 \\
\hline dwave5 & $0.052^{*}$ & $0.084^{*}$ & $0.056^{\ddagger}$ & $0.089^{*}$ & $0.062^{\dagger}$ & $0.094^{*}$ \\
\hline dwave6 & 0.003 & -0.013 & 0.010 & -0.009 & 0.014 & -0.005 \\
\hline dwave7 & 0.005 & 0.034 & 0.009 & 0.036 & 0.015 & 0.043 \\
\hline dwave8 & $0.073^{*}$ & $0.085^{*}$ & $0.078^{\dagger}$ & $0.090^{*}$ & $0.084^{*}$ & $0.095^{*}$ \\
\hline dwave9 & -0.021 & 0.014 & -0.016 & 0.020 & -0.008 & 0.026 \\
\hline dwave10 & 0.037 & 0.023 & 0.044 & 0.028 & 0.041 & 0.026 \\
\hline dwave11 & 0.007 & -0.008 & 0.013 & -0.005 & 0.020 & 0.002 \\
\hline nkids & 0.002 & 0.000 & 0.003 & 0.001 & 0.002 & 0.001 \\
\hline nwage & -0.005 & -0.007 & -0.006 & -0.008 & -0.005 & -0.008 \\
\hline tenured & -0.003 & 0.004 & 0.000 & 0.008 & -0.001 & 0.007 \\
\hline lagsaved & 0.000 & 0.000 & 0.000 & 0.000 & 0.000 & 0.000 \\
\hline lagj2pay & 0.000 & 0.000 & 0.000 & 0.000 & 0.000 & 0.000 \\
\hline cons & 0.030 & 0.032 & 0.023 & 0.028 & 0.019 & 0.024 \\
\hline Anderson LM p-value & 0.000 & 0.000 & 0.000 & 0.000 & 0.000 & 0.000 \\
\hline Sargan & 0.000 & 0.000 & 0.000 & 0.000 & 0.000 & 0.000 \\
\hline Durbin-Wu-Hausman & 0.451 & 0.922 & 0.138 & 0.383 & 0.845 & 0.641 \\
\hline & $\begin{array}{ll}\text { *: } & \text { Sig } \\
\dagger: & \text { Sig } \\
\text { †: } & \text { Sig }\end{array}$ & $\begin{array}{l}\text { ficant } \\
\text { ficant } \\
\text { ficant }\end{array}$ & $\begin{array}{l}\text { the } 1 \% \\
\text { the } 5 \% \\
\text { the } 10\end{array}$ & $\begin{array}{l}\text { evel } \\
\text { evel } \\
\text { level }\end{array}$ & & \\
\hline
\end{tabular}

Table 6: Vulnerability model for SIPZ case, symmetric and asymmetric samples

and eipz cases it is clear that none of the "insurances" have any association with changes in consumption.

To summarise our findings:

- Vulnerability is more evident in the case of the (sipz) model, compared to the (eipz) model. For the former, there is significant vulnerability for all three income definitions.

- Of the insurance variables, none of them are significantly associated with changes in consumption, except for that of tenured under (eipz) model. It is therefore clear that while there may be a weak significant relationship between whether one's job is tenured or not, the other "liquid assets" have not proven to be significantly associated with changes in consumption. It is therefore not clear whether any of these assets have any "insurance" properties. 


\begin{tabular}{rrrrrrr}
\hline \hline & \multicolumn{2}{c}{ y_gross } & \multicolumn{2}{c}{ y_net } & \multicolumn{2}{c}{ y_net_ann } \\
& Sym & Asym & \multicolumn{1}{c}{ Sym } & Asym & Sym & Asym \\
\hline drincome & $0.069^{*}$ & $0.055^{*}$ & -0.004 & -0.007 & -0.008 & 0.002 \\
dwave2 & 0.012 & 0.033 & $0.093^{*}$ & $0.069^{*}$ & $0.111^{*}$ & $0.070^{*}$ \\
dwave3 & $0.054^{\dagger}$ & 0.030 & 0.029 & 0.007 & $0.049^{\ddagger}$ & 0.036 \\
dwave4 & 0.019 & 0.007 & 0.017 & -0.007 & $0.047^{\ddagger}$ & 0.023 \\
dwave5 & $0.061^{\dagger}$ & $0.057^{\dagger}$ & $0.046^{\ddagger}$ & 0.035 & $0.056^{\dagger}$ & $0.052^{\dagger}$ \\
dwave6 & 0.027 & 0.013 & $0.050^{\ddagger}$ & 0.031 & 0.020 & 0.025 \\
dwave7 & 0.012 & 0.013 & $0.077^{\ddagger}$ & 0.045 & 0.052 & 0.063 \\
dwave8 & $0.064^{\dagger}$ & 0.038 & $0.066^{\dagger}$ & 0.042 & $0.074^{*}$ & $0.087^{*}$ \\
dwave9 & -0.007 & 0.010 & 0.023 & 0.013 & 0.033 & 0.025 \\
dwave10 & $0.046^{\ddagger}$ & 0.031 & 0.034 & -0.013 & 0.009 & -0.001 \\
dwave11 & 0.009 & -0.004 & 0.036 & 0.013 & 0.008 & 0.003 \\
nkids & 0.000 & -0.006 & -0.007 & -0.002 & 0.001 & 0.004 \\
nwage & -0.004 & 0.000 & -0.006 & -0.007 & 0.005 & -0.001 \\
tenured & -0.011 & -0.011 & -0.021 & $-0.030^{\dagger}$ & -0.017 & -0.014 \\
lagsaved & 0.000 & 0.000 & 0.000 & 0.000 & 0.000 & 0.000 \\
lagj2pay & 0.000 & 0.000 & 0.000 & 0.000 & 0.000 & 0.000 \\
cons & 0.029 & $0.043^{\ddagger}$ & 0.026 & $0.046^{\ddagger}$ & 0.009 & 0.027 \\
\hline Anderson LM p-value & 0.000 & 0.000 & 0.000 & 0.000 & 0.000 & 0.000 \\
Sargan & 0.000 & 0.000 & 0.000 & 0.000 & 0.000 & 0.000 \\
Durbin-Wu-Hausman & 0.543 & 0.023 & 0.356 & 0.834 & 0.964 & 0.872 \\
\hline & $*:$ & Significant at the $1 \%$ level & & \\
& $\dagger:$ Significant at the $5 \%$ level & & \\
& $\ddagger$ Significant at the $10 \%$ level & & \\
\hline \hline
\end{tabular}

Table 7: Vulnerability model for EIPZ case, symmetric and asymmetric samples 
- There continues to be wave-specific shocks impinging upon the income stream which are driving the vulnerability dynamics. In both cases, there is no clear pattern for which subsample, or income definition they are significant for. However, for both cases Waves 5 and 8 are significant, thereby indicating economy-wide shocks having had a significant impact in those specific years. ${ }^{11}$

What is interesting is that the vulnerability dynamics observed are quite robust to the choice of the poverty zone definition. It does not matter much whether the poverty zone was symmetric or asymmetric; the vulnerability dynamics are pretty much the same. Likewise, results are similar for both sipz and eipz subsamples. It is not surprising that with a more stricter definition of vulnerability with the case sipz case, that significant vulnerability is more evident. What is, however, clear is that there are different vulnerability outcomes depending upon the income definition. The income definition therefore matters. We find lesser "vulnerability" with the monthly net income than the monthly gross income. This suggests that the transfers and benefits assist in smoothing the shock to consumption.

\section{Interpretation}

I have identified some income quantiles that have a significant vulnerability co-efficient using a number of income definitions and smoothing "variables". For the policy maker, these empirics shed new light on how to provide assistance to the vulnerable. Traditional poverty alleviating tools used by the welfare policy maker include favourable credit schemes, incentives for saving and asset building, in addition to benefits and transfer schemes. In the empirics above, the former set of variables are not found to be associated with the vulnerable. However, the empirics strongly suggest that transfers and benefits assist the vulnerable (as revealed via the lack of a significant vulnerability co-efficient when using net incomes compared to a significant co-efficient with gross incomes). The policy packages for assisting the poor, and the vulnerable, are therefore different.

The welfare-for-work strategy already set out under the UK welfare provision scheme via the Working Tax Credit (previously the Working Families Tax Credit, similar to the Earning Individuals Tax Credit system in the United States) is the principle policy tool used to assist low income households ${ }^{12}$. These tax credit systems have been found to

\footnotetext{
${ }^{11}$ All the models estimated in Tables 3 to 7 have been also estimated using the truncated dataset, the results are identical to those presented in the paper. Scale effects due to household size have also been taken into account by estimating equivalised incomes; the above models have been estimated using the equivalised incomes and are in full agreement to the results presented in this paper. All results are available from the author and have not been presented in the paper for reasons of brevity.

${ }^{12}$ Other components of the WFTC, such as the Integrated Child Credit (ICC) scheme and an Employment Tax Credit (ETC) are similar in-work benefits that could assist the vulnerable. Wage or earning subsidies are similar benefits, where the subsidy is typically individually based and time limited.
} 
have mostly positive outcomes for households (see Blundell (2012), Dahl and Lochner (2012)). However, the conditions and criteria for selection of households eligible for the WTC have undergone several changes in recent years, and with some criticism.

At the time of the study of Waves 1-12, the WTC (then WFTC) was means-tested by income, as were benefits. (The differences in the results in significant vulnerability for gross monthly and net monthly incomes (i.e. the lack of a significant vulnerability co-efficient with the net incomes) is suggestive that the benefits and transfers assist vulnerable households in smoothing consumption. The recent revision in the eligibility criteria however has led to some distinct changes. The main perceived defect with the revised welfare/benefits system is that the participation tax rates at the lower end of the income distribution remains high; the effective marginal rate for a WTC recipient today can be over $80 \%$ (Blundell (2012)). UK eligibility for the WTC currently depends upon an hours of work condition of a minimum 16 hours per week. There is also a family eligibility criterion for children to be in full-time education or younger. In addition, there is a family net income eligibility threshold. The WTC, with Income Support and other benefits, can result in a low income earner facing very high effective tax rates. All in all, a household would gain less from being on a WTC compared to other benefits. Therefore in the current set up of the WTC, the positive effects of benefits and transfers revealed in this paper may not be applicable anymore.

While the results in this paper suggest that a means-tested criteria (on the basis of income levels) may assist the WTC recipients in smoothing their consumption, the literature on welfare and benefits suggest that higher effective tax rates indicate stronger redistribution towards low-income families with children Blundell (2012). Clearly, given the findings of this paper there is room for further research on the effectiveness of the current eligibility criteria of the WTC. Also, the empirical findings in the paper suggest further possible criteria for identifying households that should qualify (and for those in receipt of the benefit, cease to qualify) for the WTC scheme. The risks which these households are exposed to are a key to this cut-off point, alongside family income. For example, a single parent family ${ }^{13}$ is less likely to become ineligible for the tax credit over time than a coupled family. Also, in the face of an income shock, the single parent family will be less likely to cushion itself via savings (if any) compared to a coupled family with two (potential) earning members.

Including newer variables as determinants of eligibility of benefits and transfers provides us with more information about those who are likely to be in need of transfers and benefits. This is also likely, therefore, to generate a different - and potentially larger sample of individuals. For example, households under the poverty line revealed to be vulnerable (note from our estimates above that all quantiles under the poverty line are not necessarily significantly vulnerable) may have specific socio-economic characteristics

\footnotetext{
${ }^{13}$ Single parent families constitute more than $50 \%$ of WFTC recipients.
} 
which render them particularly vulnerable to an income shock. These could be the lack of assets which could be used as a "rainy day fund", or the absence of another earning member in the family. Having information on the socio-economic identity of the vulnerable, or at least having knowledge of the socio-economic characteristics of the different vulnerable quantiles, (particularly those below and just above the poverty line) would allow the policy maker to make much more informed decisions on policies to assist the vulnerable, both above and below the poverty line.

In addition to observing significant vulnerability with the gross income concept, we also observe signifcant vulnerability for net (monthly) incomes for some of the quantiles (namely, (sipz) and (eipz) quantiles). Thus, even after receipt of the benefits, some households remain vulnerable. This points to there being room for further improvement in how the eligbility criteria are devised for the transfers and benefits provided.

Another interesting finding that is worthy of future research is that significant vulnerability is least evident for the annual net income variable. This points towards vulnerability in being a short term phenomenon, not observed over the medium-to-long term. Some preliminary tests undertaken splitting income into its permanent and transitory components also show that the transitory income component is associated with significant vulnerability and not permanent income (results available from author). This finding conforms with the extant literature (Hall and Mishkin (1982), Campbell and Deaton (1989) , Attanasio and Pavoni (2011)) that consumption reacts too little to permanent income shocks and mostly to transitory income shocks. On the other hand, the textbook permanent income hypothesis assumes that personal saving is the only mechanism available to households to smooth shocks to the income stream. The evidence in this paper is that it does not do so - savings is found to be only occasionally associated with significant vulnerability. This is also evident for the preliminary tests undertaken with permanent and transitory income components. This result is therefore not in agreement with either the textbook permanent income hypothesis assumption, nor with Deaton (1992) where self-insurance by borrowing and savings can smooth consumption for a shock to transitory income.

\section{Conclusion}

In this paper I have modelled the vulnerability dynamics of UK households using the British Household Panel Survey. I was particularly interested in identifying the location of the vulnerable in the income distribution and observing the effects of "insurances" or smoothing devises that are available to households. FGLS is used to identify the vulnerable for which volatile incomes translate into volatile consumption patterns, at different parts of the income distribution. I observe that vulnerability is significantly associated with economy-wide shocks (captured by year-specific dummies), household 
composition and also the nature of insurances to which they may have access to. Most importantly, different income concepts have different stories to tell: expenditure changes are significantly associated with income changes when "income" is monthly gross income; but the vulnerability relationship defined for net income is less evident.

That I do not observe significant vulnerability regularly with the net income concept, implies that benefits and transfers successfully serve to cushion income shocks, as also revealed in Bandyopadhyay and Cowell (2007). This is particularly the case when observing the effects of different kinds of consumption smoothing mechanisms - in particular for savings and earnings from second jobs. The results suggest that these smoothing devices (i.e., savings and earnings from second jobs) may not be sufficient to cushion the effect of income shocks for vulnerable households. The distinctly different results (for some income quantiles) using gross and net income concepts clearly point towards policy successes of the transfer systems currently in place (such as the WFTC). Income quantiles for which we obtain significant vulnerability for both gross and net incomes ${ }^{14}$ are therefore households for whom the transfers and benefits have not been successful in smoothing income shocks, in addition to their own smoothing mechansims (for example, via household composition). It is these households which require the particular attention of the welfare system.

While these empirics suggest that "the vulnerable" are different from "the poor" (though, one can be both poor and vulnerable), and that vulnerability is most likely limited to particular parts of the income distribution (i.e., around the poverty line) I would not interpret vulnerability as simply a "locational device". Identifying the vulnerable is more than just identifying their level of household income, however income may be defined; the vulnerable are characterised by the lack of smoothing mechanisms at their disposal in the face of an income shock. Thus, a description of the "vulnerable household" is incomplete without a characterisation of their consumption smoothing story. The definition of "the vulnerable" is therefore subject to country specific conditions, and will vary across countries, and perhaps between regions within countries. Identifying the vulnerable and successful welfare targetting is incomplete without identifying the source of the vulnerability.

\section{References}

Amin, S., A. S. Rai, and G. Topa (2003). Does microcredit reach the poor and vulnerable? evidence from northern Bangladesh. Journal of Development Economics 70, $59-82$.

Attanasio, O. P. and N. Pavoni (2011). Risk sharing in private information models with

\footnotetext{
${ }^{14}$ These pertain to households around the poverty line.
} 
asset accumulation: Explaining the excess smoothness of consumption. Econometrica $79(4), 1027-1068$.

Bandyopadhyay, S. and F. A. Cowell (2007). Modelling vulnerability in the u.k. Technical report, Distribution Analysis Research Programme Discussion Paper Series, No. 92, STICERD, London School of Economics.

Bane, M. J. and D. T. Ellwood (1986). Slipping into and out of poverty: The dynamics of spells. Journal of Human Resources 21, 1-23.

Bardasi, E. and S. P. Jenkins (2004). Documentation for derived current and annual net household income variables. mimeo, Institute for Social and Economic Research, University of Essex, Colchester CO4 3SQ.

Blundell, R. (2012). Tax policy reform: The role of empirical evidence. Journal of the European Economic Association 10(1), 43-77.

Blundell, R., L. Pistaferri, and I. Preston. (2008). Consumption inequality and partial insurance. American Economic Review 98(5), 1887-1921.

Blundell, R. and I. Preston (1998). Consumption inequality and income uncertainty. The Quarterly Journal of Economics 113, 603-640.

Campbell, J. and A. Deaton (1989). Why is consumption so smooth? The Review of Economic Studies 56, 357-373.

Chaudhuri, S., J. Jalan, and S. Suryahadi (2002). Assessing household vulnerability to poverty from cross-sectional data: A methodology and estimates from Indonesia. Department of Economics Discussion Paper Series 0102-52, Columbia University, New York, NY 10027.

Chen, S. and M. Ravallion (2010). The developing world is poorer than we thought, but no less successful in the fight against poverty. The Quarterly Journal of Economics 125(4), 1577-1625.

Cochrane, J. (1991). A simple test of consumption insurance. Journal of Political Economy 99, $957-976$.

Communities, R. and V. Panel" (2012). After the riots: The final report of the riots communities and victims panel. Technical report, UK Government.

Dahl, G. and L. Lochner (2012). The impact of family income on child achievement; evidence from the earned income tax credit. American Economic Review 102(5), $1927-1956$.

Deaton, A. (1992). Understanding Consumption. Clarendon Press, Oxford.

Deaton, A. (2010). Price indexes, inequality and the measurement of world poverty. American Economic Review 100 (1), 5-34. 
Deaton, A. and C. Paxson (1994). Intertemporal choice and inequality. Journal of Political Economy 102, 437-467.

Dercon, S. and P. Krishnan (2002). Vulnerability, seasonality and poverty in Ethiopia. Journal of Development Studies 36, 25-53.

Engels, F. (1845). The Conditions of the Working Class in England in 1844. George Allen and Unwin.

Glewwe, P. and G. Hall (1998). Are some groups more vulnerable to macroeconomic shocks than others? hypothesistests based on panel data from Peru. Journal of Development Economics 56(1), 181-206.

Hall, R. and F. Mishkin (1982). The sensitivity of consumption to transitory income: Estimates from panel data on households. Econometrica 50, 461-481.

ILO (2012). Global employment trends report. Technical report, International Labour Organisation, Geneva.

Japelli, T. and L. Pistaferri (2006). Intertemporal choice and consumption mobility. Journal of the European Economic Association 4, 75-115.

Jenkins, S. (2000). Modelling household income dynamics. Journal of Population Economics 12, 529-567.

Jenkins, S. (2011). Changing Fortunes: Income Mobility and Poverty Dynamics in Britain. OUP.

Ligon, E. and L. Schechter (2003). Measuring vulnerability. Economic Journal. 113, C95-C102.

Lokshin, M. and M. Ravallion (2000). Welfare impacts of the 1998 financial crisis in russia and the response of the public safety net. Economics of Transition 8(2), 269-295.

Mace, B. (1991). Full insurance in the presence of aggregate uncertainty. Journal of Political Economy 99, 928 - 956.

Maloney, W., C. W. and M. Bosch (2004). The distribution of income shocks during crises: An application of quantile analysis to mexico. The World Bank Economic Review 18(2), 155-174.

Meghir, C. and L. Pistaferri (2004). Income variance dynamics and heterogeneity. Econometrica 72, 1-32.

Sen, A. K. (1976). Poverty: An ordinal approach to measurement. Econometrica 44 , 219-231.

Shorrocks, A. F. (1978). The measurement of mobility. Econometrica 46, 1013-1024. 
Townsend, R. M. (1994). Risk and insurance in village India. Econometrica 62, 539591. 


\section{A Appendix}

In this section I discuss the derivation of the estimates of net income, as described in (Bardasi and Jenkins 2004) The following definitions are provided.

- Total household net income $=$ Total household labour income

+Total household investment

+Total household pension income

+Total household benefit income

+Total household transfer income

+Local Taxes.

- Total household labour income is estimated by the following:

Total household labour income $=$ Total household gross labour earnings - Deductions, where

Total household gross labour earnings $=$ Head of household (hoh): gross earnings from employment

+Spouse of hoh (where present): gross earnings from employment

+Hoh: gross earnings from self employment

+Spouse of hoh (where present): gross earnings from self employment

+Other gross labour income (earnings of other household members + occasional earnings of head \& spouse if they have no main job).

Deductions: Income tax + national insurance contributions + pension contributions of all household members.

The definition of annual net household income is very similar to that for the current net household income variable, except for the following exceptions. First, local taxes are not deducted from income. Second, is related to the income reference period. Annual net income refer to the 12 months interval up to September 1 of the year of the relevant interview wave. For example, the wave 6 annual income variables refer to the period 01.09.95 until 31.08.96. Third, annual net income does not include earnings from a second job (whereas they are included in current net income). 


\section{B Expenditure}

Weekly expenditure on food is available in the BHPS as actual expenditure in £s for Wave 1, and from Wave 2 onwards is coded over intervals. I convert the coded weekly expenditure into actual weekly expenditure by using the mid-point of the interval used for the code. The code provided in the BHPS is given below:

Under £10: 1

$£ 10-£ 19: 2$

$£ 20-£ 29: 3$

$£ 30-£ 39: 4$

$£ 40-£ 49: 5$

$£ 50-£ 59: 6$

$£ 60-£ 79: 7$

$£ 80-£ 99: 8$

$£ 100-£ 119: 9$

$£ 120-£ 139: 10$

$£ 140-£ 159: 11$

$£ 160$ or over: 12

\section{Insurance variables}

Here I describe the insurance variables that have been used in the initial analysis to determine their individual effects on vulnerability.

- Savings, per week

- Loans: Dummy variable, whether the person has a loan or not

- Debts: Dummy variable, whether the person has debt

- Credit: Dummy variable, whether the person has credit cards, store cards.

- Mortgages: Two types of variables: Dummy variable, whether the person has a mortgage, another variable, value of old mortgage

- House Value: Value of property. 